\title{
Effects of ghrelin on anorexia in tumor-bearing mice with eicosanoid-related cachexia
}

\author{
WENHUA WANG, MARIANNE ANDERSSON, BRITT-MARIE IRESJÖ, \\ CHRISTINA LÖNNROTH and KENT LUNDHOLM
}

\author{
Surgical Metabolic Research Laboratory at Lundberg Laboratory for Cancer Research, \\ Department of Surgery, Sahlgrenska University Hospital, Göteborg University, Göteborg, Sweden
}

Received December 23, 2005; Accepted February 15, 2006

\begin{abstract}
Ghrelin is a novel brain-gut peptide that stimulates food intake and may secondarily increase body weight via a growth hormone secretagogue receptor (GHS-R). Tumorbearing mice (MCG101), characterized by anorexia, fat loss and muscle wasting due to increased concentration of $\mathrm{PGE}_{2}$ and proinflammatory cytokines (IL-1ß, IL-6, TNF- $\alpha$ ), were provided ghrelin i.p. at a low (20 $\mu \mathrm{g} /$ day) and high dose (40 $\mu \mathrm{g} /$ day) to examine the ability of ghrelin to counteract tumor-induced anorexia. Immunohistochemical staining and Western blot analyses were used to identify GHS-R expression in the brain as well as its relationship to NPY expression in hypothalamic neurons. GHS-R mRNA in hypothalamus and ghrelin mRNA in gastric fundus were quantified by RT-PCR. Body composition was determined by carcass extractions. GHS-R expression in hypothalamus and plasma ghrelin levels were significantly increased in freely-fed tumor-bearing mice, while gastric fundus expression of ghrelin was unaltered compared to non-tumor-bearing mice (controls). Ghrelin treatment increased food intake, body weight and whole body fat at both low and high doses of ghrelin in normal controls, while tumor-bearing mice showed improved intake and body composition at the high dose of ghrelin only. Exogenous ghrelin normalized the GHS-R expression in hypothalamus from tumor-bearing mice without alterations in the gastric fundus expression of ghrelin. Tumor growth was not altered by exogenous ghrelin. Our results indicate that MCG 101bearing mice became ghrelin resistant despite upregulation of hypothalamic GHS-R expression, which confirms similar indirect observations in cancer patients. Thus, other factors downstream of the ghrelin-GHS-R system appear to be more important than ghrelin to explain cancer-induced anorexia.
\end{abstract}

Correspondence to: Professor Kent Lundholm, Department of Surgery, Sahlgrenska University Hospital, SE 41345 Göteborg, Sweden

E-mail: kent.lundholm@surgery.gu.se

Key words: anorexia, ghrelin, cancer, cachexia

\section{Introduction}

Anorexia is a major factor behind progressive weight loss in cancer (1) and the mechanisms behind it are not well understood. Ghrelin, a circulating endogenous hormonal ligand to the growth hormone secretagogue receptor (GHS-R), is synthesized primarily in X/A-like endocrine cells in gastric oxyntic glands in fasting conditions. Ghrelin may therefore act as a counter-regulatory orexigenic signal to hypothalamus during the negative energy balance in cancer (2-9). GHS-R is expressed in the arcuate (ARC), paraventricular (PVN), and ventromedial $(\mathrm{VMH})$ hypothalamic nuclei $(10-12)$ in the brain, which are all implied in body weight control. Thus, ghrelin may offer a possibility to improve appetite in weight losing tumor-bearing hosts. Plasma ghrelin is reported to be negatively correlated to body weight and was consequently elevated in patients on a low-calory diet $(6,13)$ and in anorexic cancer patients $(14,15)$. Thus, fasting elevates circulating ghrelin based on increased gastric production concurrently with elevated hypothalamic GHS-R mRNA expression $(16,17)$. Accordingly, ghrelin can stimulate food intake following both systemic (ip.) and intracerebroventricular (ICV) provision with subsequent weight gain $(8,18)$. Meal intake and food appreciation were also reported to be improved following acute short-term infusion of ghrelin to cancer patients with anorexia (19). However, the results of ghrelin provision to tumor-bearing animals are not unanimous so far. Peripheral ghrelin administration increased food intake and suppressed weight loss in human melanoma-bearing nude mice (20), while only a melanocortin receptor antagonist (SHU9119) completely reversed cancer anorexia in tumor-bearing rats without any improved effects by ghrelin and neuropeptide $\mathrm{Y}$ (NPY) (15). Therefore, the effects of ghrelin on appetite control and body composition deserve additional study to understand the possibilities and limitations in therapeutic application. The present study evaluates effects by ghrelin on food intake, body composition and tumor growth in relationship to hypothalamic expression of GHS-R and gastric fundus expression of ghrelin in tumor-bearing mice following i.p. provision of low and high doses of exogenous ghrelin.

\section{Materials and methods}

Animal experiments. The experimental protocol was approved by the Committee for Ethics at the Göteborg University. Adult 
female age-matched C57BL/6 mice (16-18 g) (Taconic M\&B $\mathrm{A} / \mathrm{S}$, Denmark) were housed in plastic cages in a temperature controlled room with a 12-h dark/light cycle. The animals received laboratory rodent chow (B\&K Universal AB, Stockholm, Sweden) and tap water ad libitum for 14 days before the experiments. Mice were separated into groups of 3-4 mice per cage with a wire floor. The groups were as follows: sham-injected tumor-bearing (TB), tumor-bearing on low-dose ghrelin (TB-GhL, $20 \mu \mathrm{g} /$ day), and tumor-bearing on high-dose ghrelin (TB-GhH, $40 \mu \mathrm{g} /$ day). Non-tumorbearing freely-fed controls (FF) received either sham injection or low- (FF-GhL) or high-dose ghrelin (FF-GhH). All groups were allowed 3 days to adapt to the wire-floor cages before the start of the experiments. The experimental procedure started on day 0 with either tumor or sham implantation under general anesthesia [a combination of Ketalar ${ }^{\circledR}$ ketamine hydrochloride (Warner Larbert Nordic AB, Solna, Sweden), $100 \mathrm{mg} / \mathrm{kg}$ i.p., and Rompun ${ }^{\circledR}$ xylazine hydrochloride (Bayer Sverige AB, Göteborg, Sweden), 5 mg/ kg, i.p.].

Tumor-bearing mice were implanted s.c bilaterally in the flank with 3-5 $\mathrm{mm}^{3}$ of a transplantable MCG-101 methylcholanthrene-induced sarcoma. Non tumor-bearing mice were sham implanted. All animals had free access to chow and water ad libitum during the entire experiment. Daily food intake and body weight were registered between 0800 and 0900. From day 6, ghrelin (rat, mouse, 031-31; Phoenix pharmaceuticals, Belmont, CA, USA) was administered i.p. at $10 \mu \mathrm{g} / 100 \mu \mathrm{l}$ saline (low dose) and $20 \mu \mathrm{g} / 100 \mu \mathrm{l}$ saline (high dose), twice daily at 08:00 and 17:00 h. The control groups were administered $100 \mu \mathrm{l}$ saline. All mice were sacrificed on day 10 after tumor implantation, $15 \mathrm{~h}$ after the final administration of ghrelin. Blood samples were obtained by cardiac puncture during general anesthesia. Plasma was removed immediately for total ghrelin and $\mathrm{PGE}_{2}$ determination. Fresh brain hypothalamus and gastric fundus tissue were collected for RT-PCR and Western blot analysis of GHS-R and ghrelin respectively. Body composition was analyzed and body or carcass dry weight (exclude tumor), and whole body fat and tumor dry weight were determined as described (21).

In some mice, brains were rapidly removed and placed for 20-24 h of post-fixation in paraformaldehyde at room temperature following saline vascular bed rinsing and 20-ml room-temperature $4 \%$ paraformaldehyde perfusion for GHS-R and NPY immunohistochemistry staining. The specimens were paraffin-embedded and cut into $8-\mu \mathrm{m}$ sections for subsequent use. The arcuate (ARC), paraventricular (PVN) and ventromedial hypothalamic nuclei (VMH) were located according to Franklin and Paxinos (22) and verified by light microscopy of sections stained with Wright's hematoxylin in sequential sections.

RNA isolation and quantification. Brain hypothalamus tissue, snap-frozen in liquid nitrogen or kept in RNA-later, was homogenized and total RNA was extracted using an RNeasy lipid tissue kit (Qiagen). Gastric fundus tissue, kept in RNAlater, was homogenized and total RNA was extracted using an RNeasy fibrous tissue kit (Qiagen). Total RNA samples were treated with DNAse 1 prior to the RT reaction to remove genomic DNA contamination before RT-PCR analysis. Total
RNA concentration was estimated by spectrophotometry. The quality and quantity of RNA were always checked using an Agilent 2100 Bioanalyzer before quantification of GHS-R transcripts following the protocol of the RNA 6000 nano assay kit, where the ratio of $28 \mathrm{~S}$ and $18 \mathrm{~S}$ rRNA was determined.

cDNA synthesis and quantification. One microgram of total RNA was reverse transcribed using oligo d(T)-primer and the Moloney murine leukemia virus (MMLV) reverse transcriptase according to kit instructions (1st strand cDNA synthesis kit, Clontech). The efficiency of the cDNA synthesis and the quality of RNA were estimated in parallel by PCR using Clontech's positive control amplimer. Glyceraldehyde 3-phosphate dehydrogenase (GAPDH) was used as a house-keeping gene, checked as constant among the animal groups. Control RNA from human placenta was used as positive control. For cDNA synthesis, a parallel reaction was performed with samples taken at random without reverse transcriptase (RT) and utilized in PCR as a negative control. Analysis of amplicons was run on an Agilent 2100 Bioanalyzer following the protocol of the DNA 1000 assay kit to quantify the cDNA amount.

PCR amplification and quantification. Specific sense and antisense primers for GHS-R and ghrelin were based on mammalian GHS-R and ghrelin cDNA sequences (23). The sense primer for GHS-R was 5'-CTG CTC TGC AAA CTC TTC C-3' and the antisense primer was 5' CTT CCT CCC GAT GAG ACT GT-3'; product size 375 bp. PCR amplification was performed using initialization at $94^{\circ} \mathrm{C}$ for $2 \mathrm{~min}, 32$ cycles of $94^{\circ} \mathrm{C}$ for $30 \mathrm{sec}, 62^{\circ} \mathrm{C}$ for $30 \mathrm{sec}, 72^{\circ} \mathrm{C}$ for $30 \mathrm{sec}$, and a final elongation step for $10 \mathrm{~min}$ at $72^{\circ} \mathrm{C}$. The sense primer for ghrelin was 5'-CCA TCT GCA GTT TGC TGC TA-3' and the antisense primer was 5'-CGG ATG TGA GTT CTT GCT CA-3'; product size 394 bp. PCR amplification was performed using initialization at $94^{\circ} \mathrm{C}$ for $2 \mathrm{~min}, 28$ cycles of $94^{\circ} \mathrm{C}$ for $30 \mathrm{sec}, 61.5^{\circ} \mathrm{C}$ for $30 \mathrm{sec}, 68^{\circ} \mathrm{C}$ for $30 \mathrm{sec}$, and a final elongation step for $5 \mathrm{~min}$ at $68^{\circ} \mathrm{C}$. The primers were synthesized by Scandinavian Gene Synthesis AB, Sweden. Optimal numbers of amplification cycles were determined when analyzing the relationship between PCR cycles and product accumulation to ensure that PCR was within the area of linear amplification. Temperatures were optimized using a Mastercycler gradient (Eppendorf). Predicted long fragments were amplified under various cycle conditions.

PCR reactions were performed using a BD Advantage ${ }^{\mathrm{TM}}$ 2 PCR kit (BD Biosciences Clontech), with a concentration of $0.2 \mathrm{mM}$ of each dNTP (dATP, dCTP, dGTP, dTTP), SA PCR buffer [10 mM Tris- $\mathrm{HCl}(\mathrm{pH} 8.5), 50 \mathrm{mM} \mathrm{KCl,} 2 \mathrm{mM}$ $\left.\mathrm{MgCl}_{2}\right]$, polymerase mix including BD Titanium Taq DNA polymerase, a small amount of proofreading polymerase, and BD Taqstart antibody $(1.1 \mu \mathrm{g} / \mu \mathrm{l})$ in storage buffer at a final glycerol concentration of $1.0 \%$ : Tris- $\mathrm{HCl}(\mathrm{pH} 8.0) 0.3 \mathrm{mM}$, $\mathrm{KCl} 1.5 \mathrm{mM}$, EDTA $1.1 \mu \mathrm{M}, 0.4 \mu \mathrm{M}$ of each primer (sense and antisense) and $1 \mu \mathrm{l}$ cDNA to a final volume of $20 \mu \mathrm{l}$. A negative control for the PCR reaction without cDNA was used. PCR products were checked in an Agilent 2100 Bioanalyzer following the protocol of the DNA 1000 assay kit for quantification. The results were expressed by ratio to the value of GAPDH [GHS-R or Ghrelin/GAPDH $\left.\left(\mathrm{nmol} / \mathrm{nmol} \cdot 10^{2}\right)\right]$. 


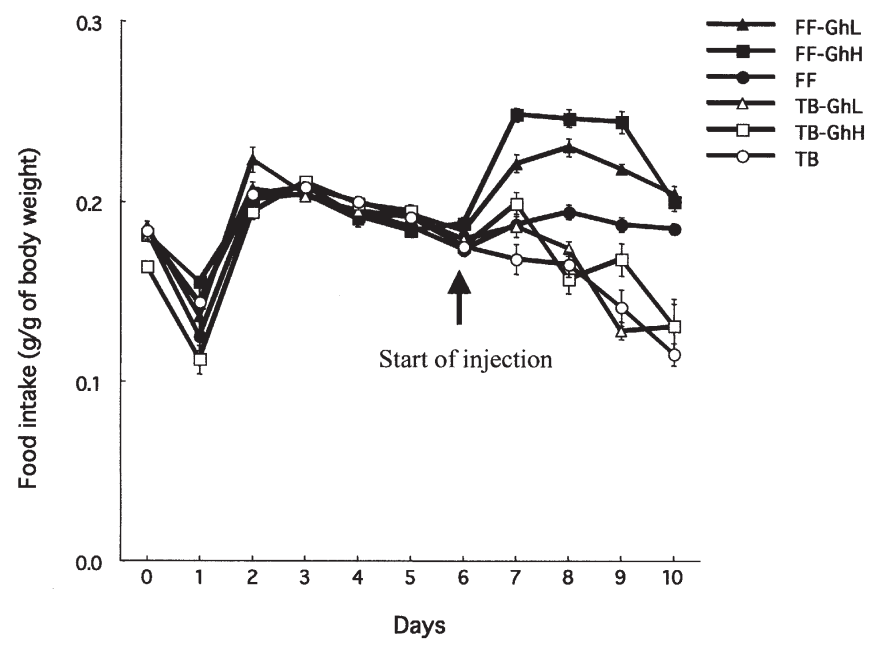

Figure 1. Time-course changes of food intake in freely-fed non-tumorbearing (FF) and tumor-bearing mice (TB) on treatment with low- $(\mathrm{GhL})$ and high- dose $(\mathrm{GhH})$ grehlin (among groups over time $\mathrm{p}<0.01$; within groups over time $\mathrm{p}<0.01$; interaction between group and time $\mathrm{p}<0.01 ; \mathrm{n} \geq 7$ mice in each group).

Western blot analysis. Fresh brain tissue was homogenized using a glass homogenizer in RIPA buffer $(50 \mathrm{mM}$ Tris- $\mathrm{HCl}$ at $\mathrm{pH} 8.0,0.1 \%$ sodium dodecyl sulfate, $1 \%$ Nonidet P-40, $150 \mathrm{mM} \mathrm{NaCl}$, and $0.5 \%$ deoxycholic acid) containing $1 \mathrm{mM}$ phenylmethylsulfonyl fluoride (Sigma Aldrich, St. Louis, MO, USA) and then centrifuged at 15,000 g for $15 \mathrm{~min}$. The protein concentrations of the supernatants were determined with the Coomassie Protein plus assay (Bio-Rad Laboratories Inc., Hercules, CA, USA). Equal amounts of each sample were separated by electrophoresis in 4-12\% Neutral PH BisTris sodium dodecyl sulfate-polyacrylamide gels (Invitrogen). Gels were blotted onto PVDF membranes (Bio-Rad). The membranes were incubated overnight at $4{ }^{\circ} \mathrm{C}$ with the antibody against GHS-R (Santa Cruz Biotechnology, Inc., CA, USA) (1:200 dilution). Immunocomplexes were visualized using the ECL Western blotting analysis system (Amersham Pharmacia Biotech).
Plasma ghrelin and $P G E_{2}$. Plasma total ghrelin was analyzed using an RIA kit (GHRT-89HK) from LINCO Research, MO, USA, with quality control values within an expected range. The coefficient of variation was $<10 \%$ with a sensitivity of $93 \mathrm{pg} / \mathrm{ml} \mathrm{PGE}_{2}$ was analyzed as described elsewhere $(24,25)$.

Immunohistochemistry. Immunohistochemical staining was optimized: antigen retrieval was accomplished by trypsination. Primary antibodies were diluted in 1\% TBS-BSA containing $0.1 \%$ Saponin (1:100; rabbit anti-human GHS-R polyclonal antibody, sc-20748; Santa Cruz Biotechnology; 1:100; sheep anti-neuropeptide Y polyclonal antibody, AB1583; Chemicon International, Inc, CA, USA) and incubated overnight (20 h) at room temperature after blocking non-specific protein binding sites with 5\% BSA for $30 \mathrm{~min}$. Secondary antibodies [Alexa Fluor ${ }^{\circledR} 594$ goat anti-rabbit IgG $(\mathrm{H}+\mathrm{L})$, A-11037; Alexa Fluor ${ }^{\circledR} 488$ donkey anti-sheep IgG $(\mathrm{H}+\mathrm{L})$, A-11015; Molecular Probes, Inc., OR, USA] were diluted 1:300 with $1 \%$ TBS-BSA containing $0.1 \%$ Saponin and incubated for $1 \mathrm{~h}$ at room temperature. Double immunolabeling was detected with the aid of a fluorescence microscope (Y-FL, Nikan, Japan) using a Tx RED, FITC and D-F-T filter cube for detection of Alexa 594 and Alexa 488 separately or together.

Parallel negative controls were confirmed by using diluant instead of primary antibody. Control stainings were undertaken with either the first or the second antibody as well as by incubation with normal serum from the species in which the primary antibodies were raised. In addition, the specificity of the primary antibodies was tested by preincubation with corresponding blocking peptides.

Statistical analyses. Time course changes of food intake among different groups were compared by ANOVA for repeated measures. Statistical analyses are presented as differences among groups over time, changes within groups over time and interactions between group and time. Other comparisons were performed by ANOVA for factorial measurements. Results are presented as mean \pm SEM. A p $\leq 0.05$ was considered statistically significant in 2-tailed tests.
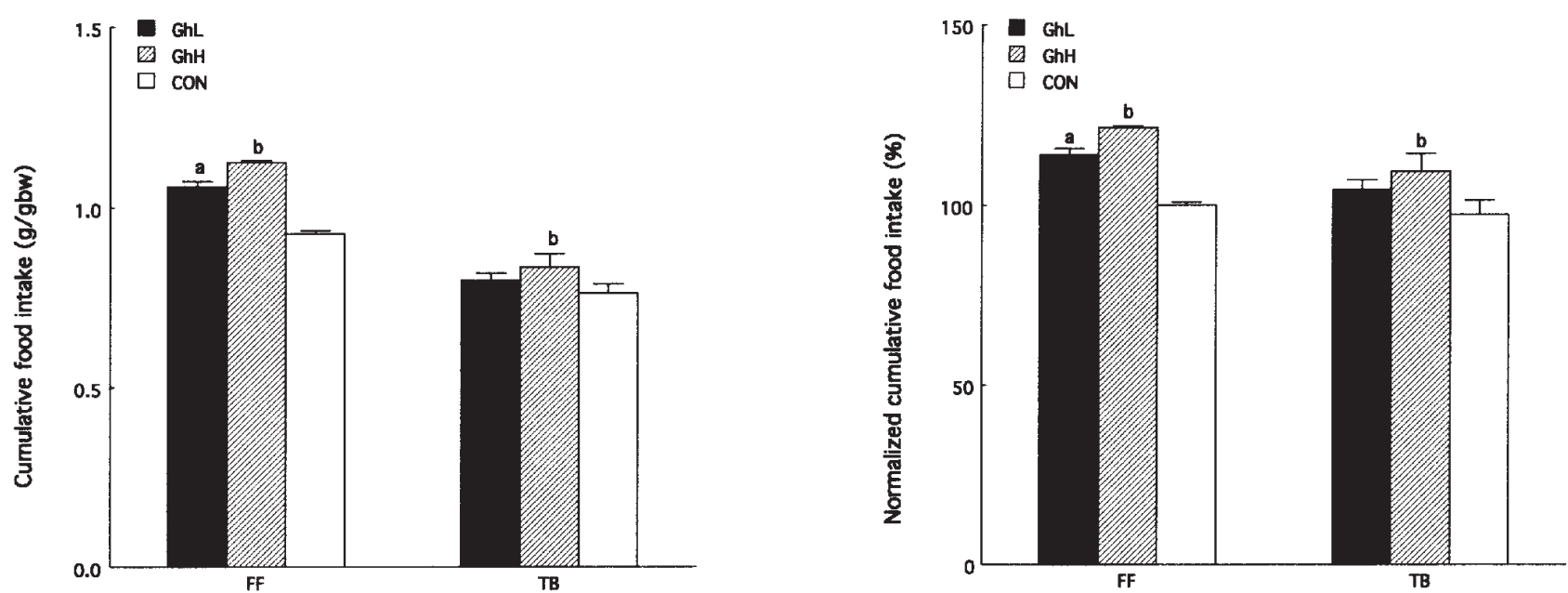

Figure 2. Cumulative food intake (g/gbw and \% of baseline intake) during the period with tumor-induced anorexia (days 6-10) in freely-fed non-tumorbearing (FF) and tumor-bearing mice (TB) on treatment with low- (GhL) or high-dose $(\mathrm{GhH})$ ghrelin $(\mathrm{a}, \mathrm{p}<0.05 \mathrm{GhL}$ vs $\mathrm{CON}$; b, p $<0.05 \mathrm{GhH}$ vs $\mathrm{CON}$; $\mathrm{n} \geq 7$ mice in each group). 

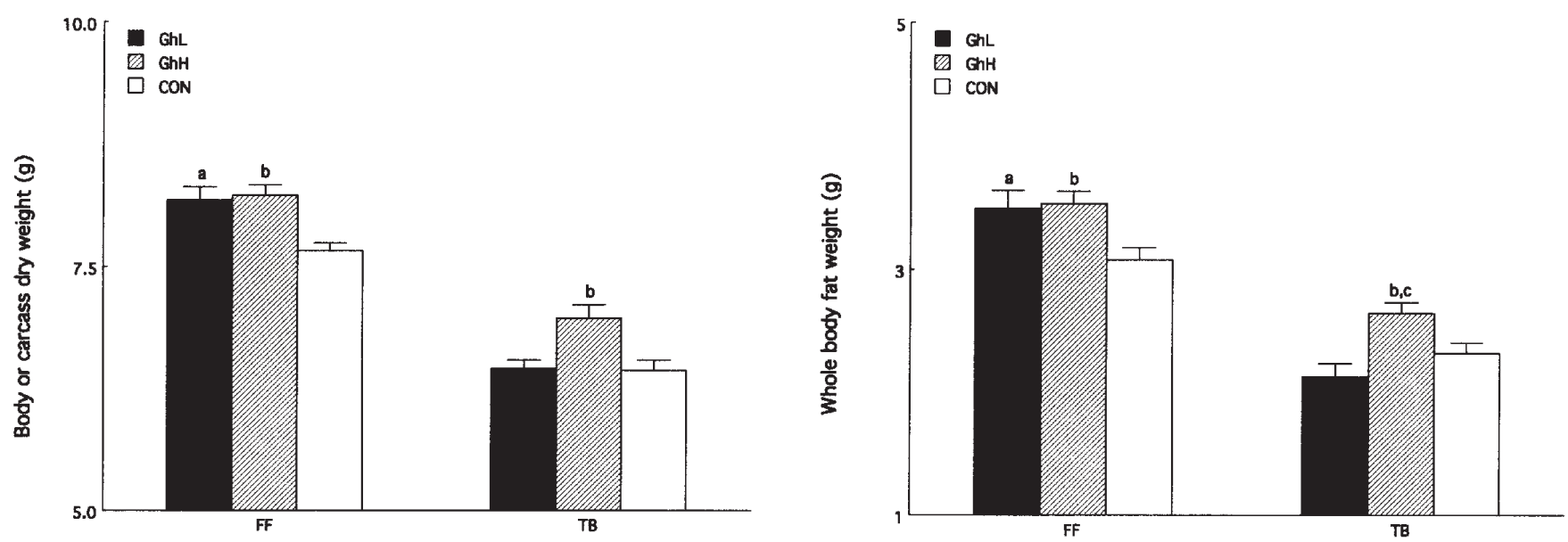

Figure 3. Body or carcass (minus tumor) dry weight and whole body fat at day 10 in freely-fed non-tumor-bearing (FF) and tumor-bearing mice (TB) on treatment with low- (GhL) or high-dose (GhH) ghrelin ( $\mathrm{a}, \mathrm{p}<0.05 \mathrm{GhL}$ vs $\mathrm{CON} ; \mathrm{b}, \mathrm{p}<0.05 \mathrm{GhH}$ vs CON; $\mathrm{c}, \mathrm{p}<0.05 \mathrm{GhH}$ vs GhL; $\mathrm{n} \geq 7 \mathrm{mice}$ in each group).

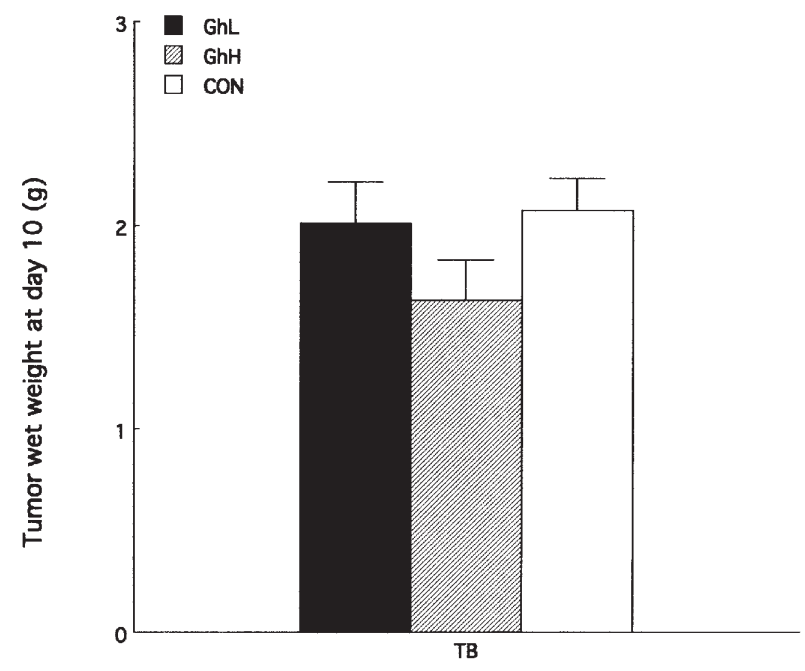

Figure 4. Tumor weight at day 10 in tumor-bearing mice (TB) on treatment with low- (GhL) or high-dose $(\mathrm{GhH})$ ghrelin $(\mathrm{p}>0.05 \mathrm{GhH}$ and $\mathrm{GhL}$ vs $\mathrm{CON} ; \mathrm{n} \geq 7$ mice in each group).

\section{Results}

Food intake. Tumor growth induced anorexia after day 5 following tumor implantation and food intake in tumor-bearing mice became significantly reduced at day 7 ( $p<0.05$, Fig. 1). Ghrelin treatment increased food intake effectively in nontumor-bearing mice but was considerably less effective in tumor-bearing mice (Fig. 1). Thus, cumulative food intake from days 6 to 10 was increased in freely-fed non-tumorbearing mice at both low and high doses of ghrelin provision ( $<<0.05$, Fig. 2), while only the high dose of ghrelin improved food intake in tumor-bearing mice ( $<<0.05$, Fig. 2).

Body composition and tumor growth. Body composition analysis showed that both low and high doses of ghrelin increased body dry weight as well as whole body fat in freelyfed non-tumor-bearing mice $(\mathrm{p}<0.05)$, while only the high dose of ghrelin improved carcass dry weight and whole body fat in tumor-bearing mice ( $p<0.05$, Fig. 3). Ghrelin treatment did not alter tumor growth ( $\mathrm{p}>0.05$, Fig. 4$)$.

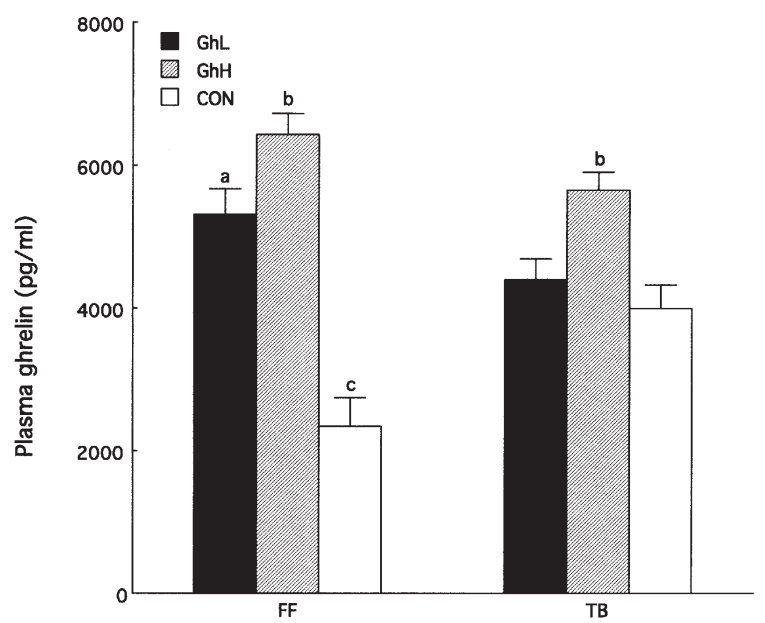

Figure 5. Total plasma ghrelin concentration $(\mathrm{pg} / \mathrm{ml})$ at day 10 in freely-fed non-tumor-bearing (FF) and tumor-bearing mice (TB) on treatment with low- (GhL) or high-dose $(\mathrm{GhH})$ ghrelin $(\mathrm{a}, \mathrm{p}<0,05 \mathrm{GhL}$ vs $\mathrm{CON}$; b, p $<0,05$ $\mathrm{GhH}$ vs $\mathrm{CON} ; \mathrm{c}, \mathrm{p}<0.05$ FF-CON vs TB-CON; $\mathrm{n} \geq 7$ mice in each group).

Plasma ghrelin and $P G E_{2}$ concentrations. Plasma total ghrelin concentrations were significantly higher in tumorbearing mice than in freely-fed non-tumor-bearing mice without provision of exogenous ghrelin $(\mathrm{p}<0.05$, Fig. 5). Plasma total ghrelin concentration was further increased in tumor-bearing mice only when the high dose of ghrelin was provided $(\mathrm{p}<0.05)$, while similar plasma increases of ghrelin were found at both low and high doses in freely-fed non-tumor-bearing mice $\left(\mathrm{p}<0.05\right.$, Fig. 5). Ghrelin treatment did not alter plasma $\mathrm{PGE}_{2}$ concentrations significantly in either freely-fed non-tumorbearing or tumor-bearing mice (Fig. 6).

GHS-R expression in hypothalamus. GHS-R expression in hypothalamus was significantly higher in untreated tumorbearing mice compared with untreated freely-fed non-tumorbearing mice $(\mathrm{p}<0.05$, Fig. 7). Low-dose ghrelin treatment did not alter GHS-R expression in hypothalamus in either freely-fed non-tumor-bearing or tumor-bearing mice, while high-dose ghrelin treatment downregulated GHS-R expression in hypothalamus of tumor-bearing mice ( $p<0.05$, Fig. 7). 


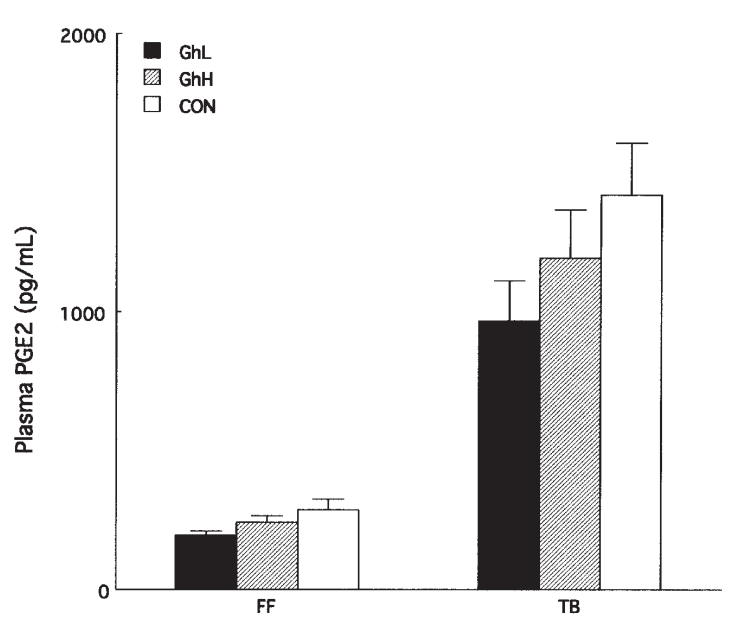

Figure 6. Plasma $\mathrm{PGE}_{2}$ concentration at day 10 in freely-fed non-tumorbearing (FF) and tumor-bearing mice (TB) on low- $(\mathrm{GhL})$ or high-dose $(\mathrm{GhH})$ ghrelin treatment vs controls $(\mathrm{CON})$ in C57BL mice $(\mathrm{n}=4$ mice in each group).

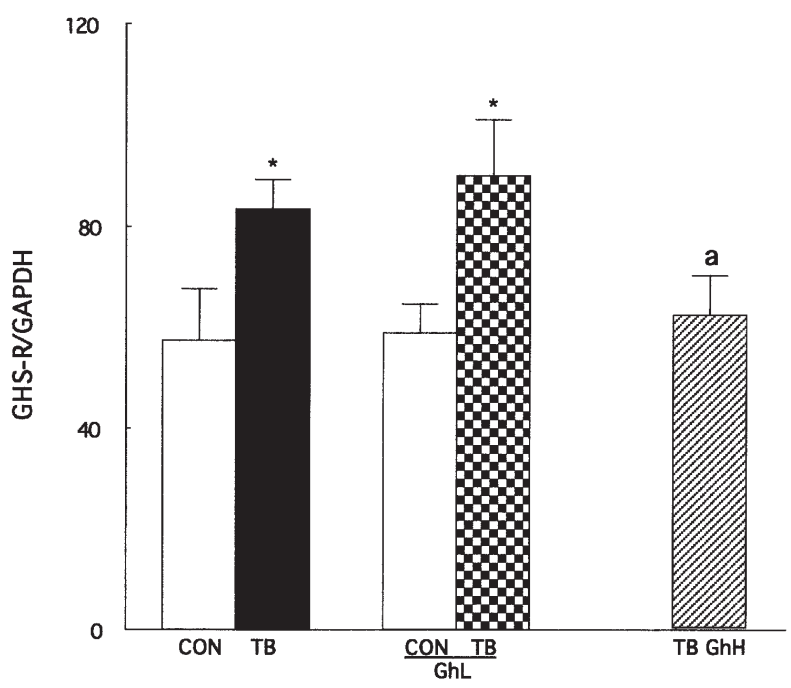

Figure 7. Growth hormone secretagogue receptor (GHS-R) 1a expression [GHS-R/GAPDH $\left.(\mathrm{nmol} / \mathrm{nmol}) \cdot 10^{2}\right]$ in brain hypothalamus at day 10 in freelyfed non-tumor-bearing $(\mathrm{CON})$ and tumor-bearing mice (TB). Expression was significantly higher in TB mice versus CON mice. In TB mice, high-dose ghrelin treatment inhibited GHS-R expression in hypothalamus but low-dose ghrelin treatment did not $\left({ }^{*} \mathrm{p}<0.05 ; \mathrm{n} \geq 7\right.$ mice in each group; $\left.\mathrm{a}, \mathrm{p}<0.05 \mathrm{vs} \mathrm{TB}\right)$.

GHS-R expression in hypothalamus was confirmed at protein level by Western blot analysis (Fig. 8). Immunohistochemical double staining demonstrated that GHS-R was co-expressed with NPY in some neurons of ARC, PVN and VMH nuclei of hypothalamus (Fig. 9).

Ghrelin expression in gastric fundus. Ghrelin expression in gastric fundus was comparable among freely-fed non-tumorbearing mice, tumor-bearing mice and tumor-bearing mice on high-dose ghrelin ( $\mathrm{p}>0.05$, Fig. 10).

\section{Discussion}

Ghrelin is a well-documented orexigenic factor with pronounced effects in regulation of energy homeostasis. Thus,
Negative control SC- $10359 \quad$ Size Marker

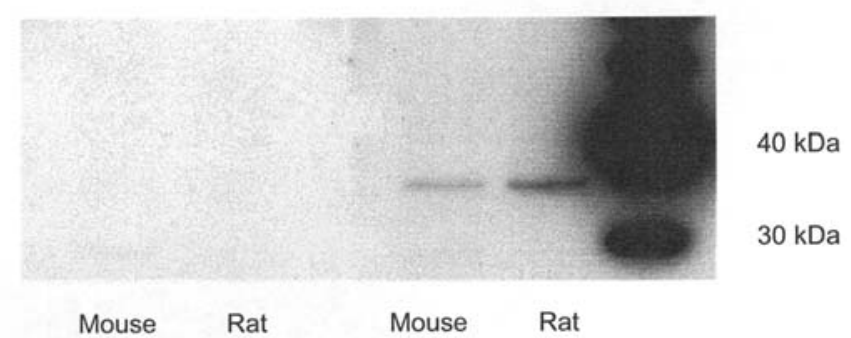

Figure 8. Western blotting of the ghrelin receptor (GHS-R) in normal mouse and Wistar rat hypothalamus (positive control). The specific band is located between 30-40 kDa.

ghrelin may stimulate food intake in rodents and humans by mechanisms other than those implicated for growth hormone administration, either centrally or peripherally $(8,18)$. It has been demonstrated that growth hormone $(\mathrm{GH})$ secretion on food intake is mediated by GHS-R type 1a, since GHS-R type 1a KO mice are unresponsive to ghrelin concerning increased appetite (26). Thus, ghrelin stimulates food intake through the release of Agouti-related protein (AgRP) and NPY in hypothalamus. It has also been found that ghrelin increases the expression of mRNA for AgRP and NPY (27) and triggers the expression of immediate early-response genes in NPY and AgRP neurons in ARC (28-30). Ghrelin induced potent orexigenic effects in NPY null mice by AgRP (31), and activated directly a population of isolated orexin neurons in lateral hypothalamus (LHA) (32). It has also been implied that ghrelin is expressed in a previously uncharacterized group of neurons in the hypothalamus. These neurons lie in the space between the ARC, PVN, VMH and LHA hypothalamic nuclei, even with projections to several nuclei outside the hypothalamus (33). In addition, GHS-R has been detected on vagal afferent neurons in the rat nodose ganglion $(34,35)$. Consequently, vagotomy would inhibit ghrelin to stimulate food intake and GH release (34). Thus, fasting-induced elevation of plasma ghrelin was reported to be completely abolished by either subdiaphragmatic vagotomy or atropine treatment (36). Accordingly, it was concluded that ghrelin signals from the stomach are transmitted to the brain via the vagus nerve and circulating ghrelin.

In the present study, we confirm that GHS-R are coexpressed with NPY on neurons in ARC, PVN and VMH, and that peripheral ghrelin (i.p.) administration stimulates food intake in a dose-dependent manner in normal mice, which caused weight gain of mainly increased adipose enlargement as reported by others $(8,18)$, while food intake of tumorbearing mice became resistant to ghrelin. Only a high dose of ghrelin improved food intake and body composition in tumorbearing mice, despite GHS-R expression in hypothalamus being increased in the basal state. However, a positive relationship was not found between increased plasma ghrelin and ghrelin mRNA expression in gastric fundus of tumorbearing mice, but the high dose of ghrelin downregulated GHS-R expression in hypothalamus of tumor-bearing mice. In line with the present findings it has been reported that circulating ghrelin is increased in human cancer patients with 

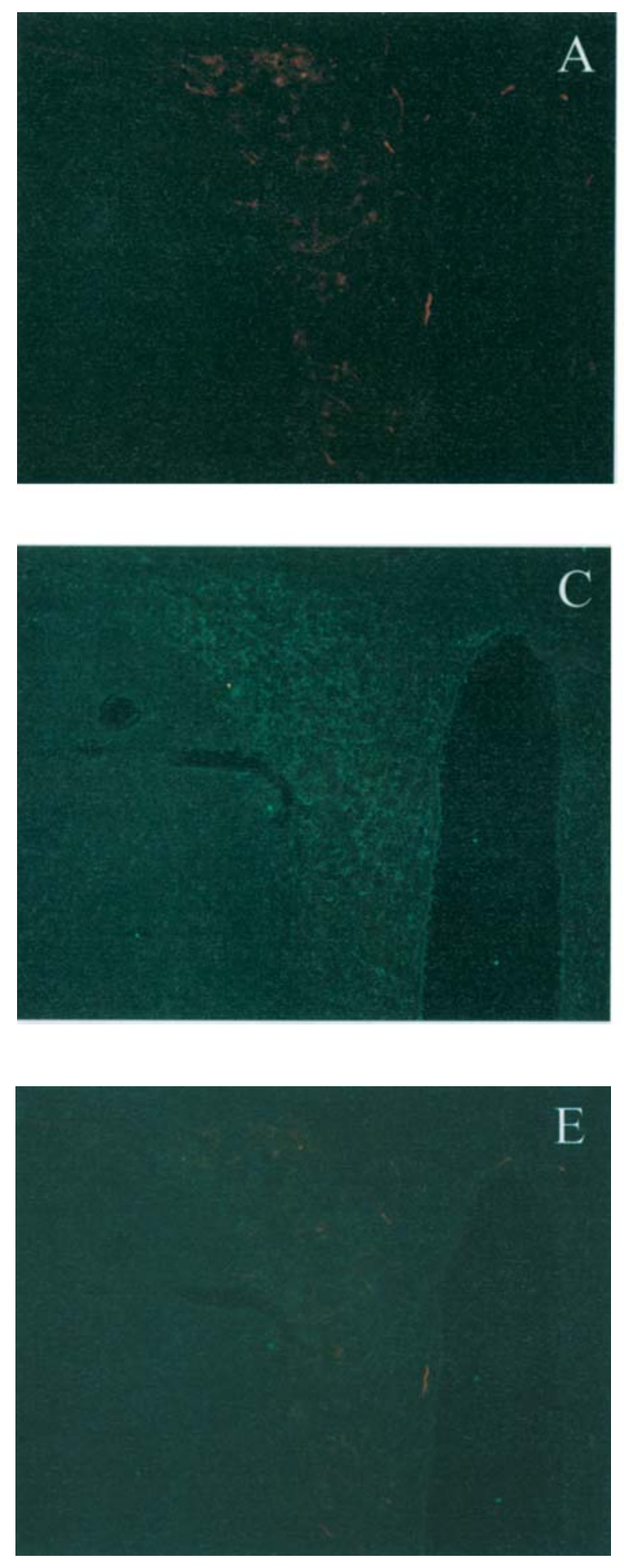

Figure 9. Immunohistochemical staining of GHS-R and NPY in PVN (X20). Black field with red signals shows GHS-R positive neurons (A) compared with the negative control (B); green signals are NYP positive neurons (C) compared with the negative control (D); both GHS-R and NYP were coexpressed in some neurons (E).

cachexia (37), and both ghrelin biosynthesis and secretion was upregulated in cachectic nude mice bearing human melanoma cells (38). Thus, circulating ghrelin may have enhanced the secretion of growth hormone which stimulated growth of muscle and bone tissue not only in normal rodents but also in cachectic rats with chronic heart failure $(29,39)$. Furthermore, the NPY mRNA level in the hypothalamus
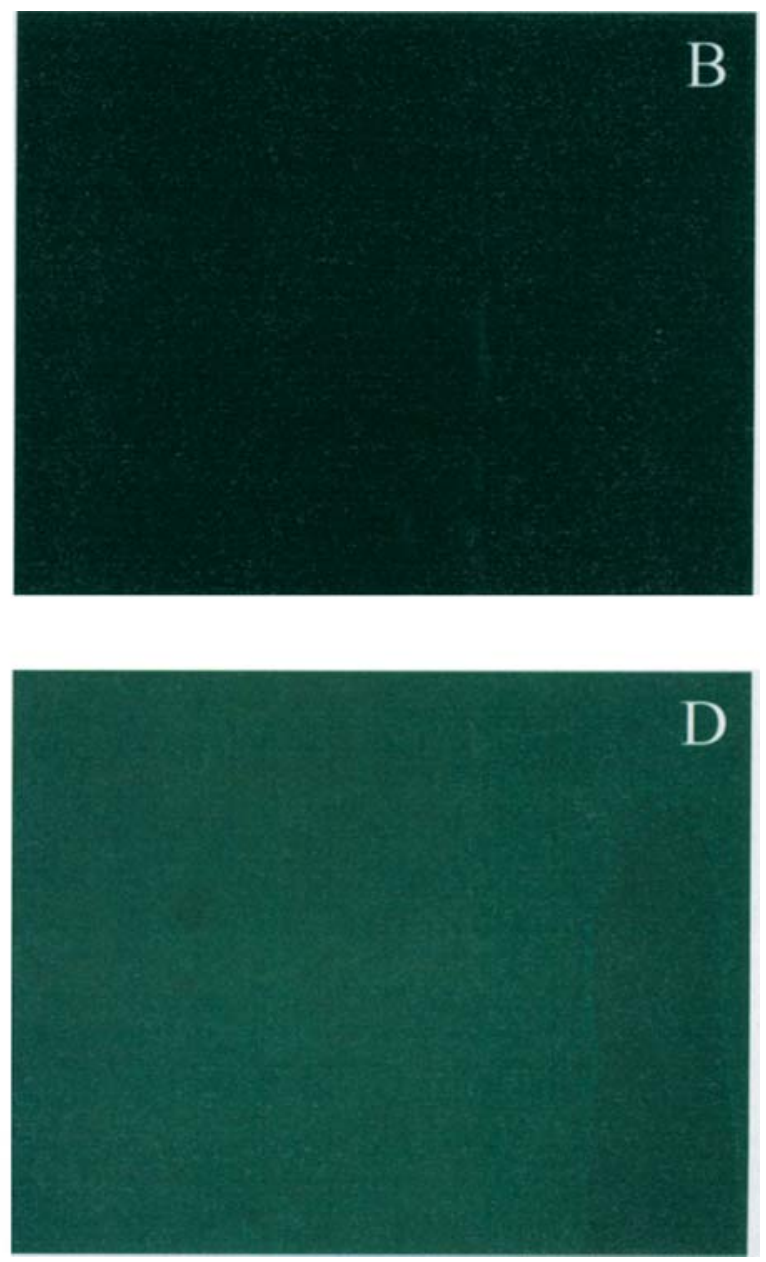

was increased in SEKI tumor-bearing mice with anorexia/ cachexia (20), and i.p. administration of ghrelin augmented hypothalamic NPY mRNA expression (40). In addition, ghrelin may also promote anti-anorexic effects by attenuation of proinflammatory cytokines and activity of nuclear factor- $\kappa \mathrm{B}$ in endothelial cells of cachectic tumor-bearing hosts (41). The current results indicate that the ghrelin-GHS-R system plays an inefficient compensatory role in cancer-induced anorexia. The effects of anorexia/cachexia-inducing factors, related to the tumor burden, may outweigh the effects of endogenous anabolic factors by circulating ghrelin, GHS-R and increased NPY in hypothalamus. Thus, cancer anorexia may be mediated via mechanisms that compete with or are downstream of ghrelin. Treatment with a central melanocortin receptor 3/4 antagonist (SHU9119) was reported to reverse cancer anorexia and increase body weight in a prostate adenocarcinoma rat model (15), suggesting that the melanocortin signaling system may be more important than ghrelin resistance to explain cancer anorexia.

The MCG tumor-bearing model is characterized by increased circulating plasma $\mathrm{PGE}_{2}$ concentrations. In previous studies, we have demonstrated that cyclooxygenase (COX) inhibitors (indomethacin) decreased tumor growth due to reduced prostanoid production in both MCG101 tumor and host tissues. This led to reduced tumor cell proliferation and increased food intake and body weight (42), in part explained by $\mathrm{EP}_{1}$ and $\mathrm{EP}_{3}$ receptor control of local MCG growth (43). 


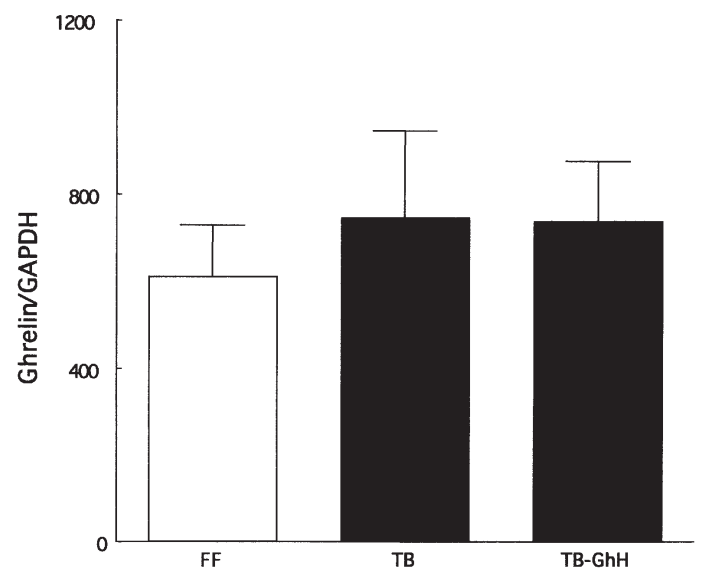

Figure 10. Ghrelin expression [Ghrelin/GAPDH(nmol/nmol.10²)] in gastric fundus at day 10 in freely-fed non-tumor-bearing (FF) and tumor-bearing mice without (TB) or with high-dose ghrelin treatment (TB-GhH) $(p>0.05$; $\mathrm{n} \geq 7$ mice in each group).

Expression of $\mathrm{EP}_{1}$ in the liver and $\mathrm{EP}_{4}$ receptor in white adipose tissue was upregulated and responded to indomethacin treatment, while downregulated expression of $\mathrm{EP}_{3}$ in skeletal muscle from tumor-bearing mice was unresponsive to indomethacin treatment despite improved carcass weight (44). In the present study, tumor growth and plasma $\mathrm{PGE}_{2}$ concentration were not significantly attenuated by ghrelin, suggesting that PGE-EP receptor signals and the ghrelin-GHS-R pathway belong to different transductions in the development of tumorinduced anorexia. Thus, a combination of COX inhibition and ghrelin administration may have additive effects on MCGinduced anorexia/cachexia.

Ghrelin may sometimes promote cell proliferation and invasiveness of cultured pancreatic adenocarcinoma cells dose-dependently (45). However, in the present study, ghrelin treatment did not alter tumor growth, indicating that MCG tumor cells are not particularly sensitive to ghrelin perhaps due to a lack of or low GHS-R expression in tumor cells (not shown).

In conclusion, plasma ghrelin concentration and GHS-R expression in hypothalamus were compensatorily increased in anorexic weight-losing MCG 101 tumor-bearing mice, indicating development of ghrelin resistance. The orexigenic effect of ghrelin was partially blunted, indicating appearance of ghrelin resistance in tumor-bearing mice. Thus, our results imply other major factors downstream of ghrelin to be highly significant to explain tumor-induced anorexia. Our present findings agree with the indirect evidence of ghrelin resistance in cancer and non-cancer patients $(14,37,46)$. Despite this resistance, ghrelin can attenuate cancer-induced anorexia/ cachexia (19).

\section{Acknowledgements}

This study was supported in parts by grants from the Swedish Cancer Society (2014), the Swedish Research Council (08712), Assar Gabrielsson Foundation (AB Volvo), Jubileumskliniken Foundation, IngaBritt \& Arne Lundberg Research Foundation, Swedish and Göteborg Medical Societies and the Medical Faculty, Göteborg University.

\section{References}

1. Ollenschlager G, Viell B, Thomas W, Konkol K and Burger B: Tumor anorexia: causes, assessment, treatment. Recent Results Cancer Res 121: 249-259, 1991.

2. Date Y, Kojima M, Hosoda H, et al: Ghrelin, a novel growth hormone-releasing acylated peptide, is synthesized in a distinct endocrine cell type in the gastrointestinal tracts of rats and humans. Endocrinology 141: 4255-4261, 2000.

3. Dickson SL and Luckman SM: Induction of c-fos messenger ribonucleic acid in neuropeptide $\mathrm{Y}$ and growth hormone $(\mathrm{GH})$ releasing factor neurons in the rat arcuate nucleus following systemic injection of the GH secretagogue, GH-releasing peptide-6. Endocrinology 138: 771-777, 1997.

4. Willesen MG, Kristensen P and Romer J: Co-localization of growth hormone secretagogue receptor and NPY mRNA in the arcuate nucleus of the rat. Neuroendocrinology 70: 306-316, 1999.

5. Schwartz MW, Seeley RJ, Campfield LA, Burn P and Baskin DG: Identification of targets of leptin action in rat hypothalamus. J Clin Invest 98: 1101-1106, 1996.

6. Cummings DE, Purnell JQ, Frayo RS, Schmidova K, Wisse BE and Weigle DS: A preprandial rise in plasma ghrelin levels suggests a role in meal initiation in humans. Diabetes 50: 1714-1719, 2001.

7. Toshinai K, Mondal MS, Nakazato M, et al: Upregulation of Ghrelin expression in the stomach upon fasting, insulin-induced hypoglycemia, and leptin administration. Biochem Biophys Res Commun 281: 1220-1225, 2001.

8. Tschop M, Smiley DL and Heiman ML: Ghrelin induces adiposity in rodents. Nature 407: 908-913, 2000.

9. Shiiya T, Nakazato M, Mizuta M, et al: Plasma ghrelin levels in lean and obese humans and the effect of glucose on ghrelin secretion. J Clin Endocrinol Metab 87: 240-244, 2002.

10. Guan XM, Yu H, Palyha OC, et al: Distribution of mRNA encoding the growth hormone secretagogue receptor in brain and peripheral tissues. Brain Res Mol Brain Res 48: 23-29, 1997.

11. Howard AD, Feighner SD, Cully DF, et al: A receptor in pituitary and hypothalamus that functions in growth hormone release. Science 273: 974-977, 1996.

12. Mitchell V, Bouret S, Beauvillain JC, et al: Comparative distribution of mRNA encoding the growth hormone secretagoguereceptor (GHS-R) in Microcebus murinus (Primate, lemurian) and rat forebrain and pituitary. J Comp Neurol 429: 469-489, 2001.

13. Hansen TK, Dall R, Hosoda H, et al: Weight loss increases circulating levels of ghrelin in human obesity. Clin Endocrinol 56: 203-206, 2002.

14. Shimizu Y, Nagaya N, Isobe T, et al: Increased plasma ghrelin level in lung cancer cachexia. Clin Cancer Res 9: 774-778, 2003.

15. Wisse BE, Frayo RS, Schwartz MW and Cummings DE: Reversal of cancer anorexia by blockade of central melanocortin receptors in rats. Endocrinology 142: 3292-3301, 2001.

16. Kim MS, Yoon CY, Park KH, et al: Changes in ghrelin and ghrelin receptor expression according to feeding status. Neuroreport 14: 1317-1320, 2003.

17. Gualillo O, Caminos JE, Nogueiras R, et al: Effect of food restriction on ghrelin in normal-cycling female rats and in pregnancy. Obes Res 10: 682-687, 2002.

18. Wren AM, Small CJ, Ward HL, et al: The novel hypothalamic peptide ghrelin stimulates food intake and growth hormone secretion. Endocrinology 141: 4325-4328, 2000.

19. Neary NM, Small CJ, Wren AM, et al: Ghrelin increases energy intake in cancer patients with impaired appetite: acute, randomized, placebo-controlled trial. J Clin Endocrinol Metab 89: 2832-2836, 2004.

20. Hanada T, Toshinai K, Kajimura N, et al: Anti-cachectic effect of ghrelin in nude mice bearing human melanoma cells. Biochem Biophys Res Commun 301: 275-279, 2003.

21. Eden E, Lindmark L, Karlberg I and Lundholm K: Role of whole-body lipids and nitrogen as limiting factors for survival in tumor-bearing mice with anorexia and cachexia. Cancer Res 43: 3707-3711, 1983.

22. Franklin K and Paxinos G: The Mouse Brain in Stereotaxic Coordinates. Academic Press, 1997.

23. Kawamura K, Sato N, Fukuda J, et al: Ghrelin inhibits the development of mouse preimplantation embryos in vitro. Endocrinology 144: 2623-2633, 2003.

24. Lönnroth C, Gelin J and Lundholm K: Expression of interleukin-6 in tumor-bearing mice with cytokine dependent cachexia. Int J Oncol 5: 329-336, 1994. 
25. Lönnroth C, Svaninger G, Gelin J, et al: Effects related to indomethacin prolonged survival and decreased tumor growth in a mouse tumor model with cytokine dependent cancer cachexia. Int J Oncol 7: 1405-1413, 1995

26. Sun Y, Wang P, Zheng H and Smith RG: Ghrelin stimulation of growth hormone release and appetite is mediated through the growth hormone secretagogue receptor. Proc Natl Acad Sci USA 101: 4679-4684, 2004.

27. Nakazato M, Murakami N, Date Y, et al: A role for ghrelin in the central regulation of feeding. Nature 409: 194-198, 2001.

28. Seoane LM, Lopez M, Tovar S, Casanueva FF, Senaris R and Dieguez C: Agouti-related peptide, neuropeptide Y, and somatostatin-producing neurons are targets for ghrelin actions in the rat hypothalamus. Endocrinology 144: 544-551, 2003.

29. Hewson AK and Dickson SL: Systemic administration of ghrelin induces Fos and Egr-1 proteins in the hypothalamic arcuate nucleus of fasted and fed rats. J Neuroendocrinol 12 . 1047-1049, 2000.

30. Wang L, Saint-Pierre DH and Tache Y: Peripheral ghrelin selectively increases Fos expression in neuropeptide Ysynthesizing neurons in mouse hypothalamic arcuate nucleus. Neurosci Lett 325: 47-51, 2002.

31. Tung YC, Hewson AK and Dickson SL: Actions of leptin on growth hormone secretagogue-responsive neurones in the rat hypothalamic arcuate nucleus recorded in vitro. J Neuroendocrinol 13: 209-215, 2001

32. Toshinai K, Date Y, Murakami N, et al: Ghrelin-induced food intake is mediated via the orexin pathway. Endocrinology 144: 1506-1512, 2003

33. Cowley MA, Smith RG, Diano S, et al: The distribution and mechanism of action of ghrelin in the CNS demonstrates a novel hypothalamic circuit regulating energy homeostasis. Neuron 37: 649-661, 2003.

34. Date Y, Murakami N, Toshinai K, et al: The role of the gastric afferent vagal nerve in ghrelin-induced feeding and growth hormone secretion in rats. Gastroenterology 123: 1120-1128, 2002.

35. Sakata I, Yamazaki M, Inoue K, Hayashi Y, Kangawa K and Sakai T: Growth hormone secretagogue receptor expression in the cells of the stomach-projected afferent nerve in the rat nodose ganglion. Neurosci Lett 342: 183-186, 2003.
36. Williams DL, Grill HJ, Cummings DE and Kaplan JM: Vagotomy dissociates short- and long-term controls of circulating ghrelin. Endocrinology 144: 5184-5187, 2003.

37. Garcia JM, Garcia-Touza M, Hijazi RA, et al: Active ghrelin levels and active to total ghrelin ratio in cancer-induced cachexia. J Clin Endocrinol Metab 90: 2920-2926, 2005.

38. Hanada T, Toshinai K, Date Y, et al: Upregulation of ghrelin expression in cachectic nude mice bearing human melanoma cells. Metabolism 53: 84-88, 2004.

39. Nagaya N, Uematsu M, Kojima M, et al: Chronic administration of ghrelin improves left ventricular dysfunction and attenuates development of cardiac cachexia in rats with heart failure. Circulation 104: 1430-1435, 2001.

40. Asakawa A, Inui A, Kaga T, et al: Ghrelin is an appetitestimulatory signal from stomach with structural resemblance to motilin. Gastroenterology 120: 337-345, 2001.

41. Li WG, Gavrila D, Liu X, et al: Ghrelin inhibits proinflammatory responses and nuclear factor-kappaB activation in human endothelial cells. Circulation 109: 2221-2226, 2004.

42. Cahlin C, Gelin J, Delbro D, Lonnroth C, Doi C and Lundholm K: Effect of cyclooxygenase and nitric oxide synthase inhibitors on tumor growth in mouse tumor models with and without cancer cachexia related to prostanoids. Cancer Res 60: 1742-1749, 2000.

43. Wang W, Andersson M, Lonnroth C, Svanberg E and Lundholm K: Anorexia and cachexia in prostaglandin EP1 and EP3 subtype receptor knockout mice bearing a tumor with high intrinsic PGE2 production and prostaglandin related cachexia. J Exp Clin Cancer Res 24: 99-107, 2005.

44. Wang W, Andersson M, Lonnroth C, Svanberg E and Lundholm K: Prostaglandin E and prostacyclin receptor expression in tumor and host tissues from MCG 101-bearing mice: a model with prostanoid-related cachexia. Int J Cancer 115: 582-590, 2005

45. Duxbury MS, Waseem T, Ito H, et al: Ghrelin promotes pancreatic adenocarcinoma cellular proliferation and invasiveness. Biochem Biophys Res Commun 309: 464-468, 2003.

46. Isomoto $\mathrm{H}$, Ueno $\mathrm{H}$, Nishi $\mathrm{Y}$, et al: Circulating ghrelin levels in patients with various upper gastrointestinal diseases. Dig Dis Sci 50: 833-838, 2005. 